\title{
A morphometric study of adult human trachea in West Bengal population
}

\author{
Datta D. ${ }^{1}$, Kundu D. ${ }^{2 *}$, Pal S. ${ }^{3}$, Das A. ${ }^{4}$ \\ DOI: https://doi.org/10.17511/ijmrr.2019.i01.07
}

${ }^{1}$ Dibyendu Datta, Medical Officer, Birpara State General Hospital, Alipurduar, West Bengal, India.

2* Dipankar Kundu, Associate Professor, Department of Biochemistry, Medical College, Kolkata, West Bengal, India.

3 Sharmila Pal, Professors \& HOD, Department of Anatomy, Medical College, Kolkata, West Bengal, India.

${ }^{4}$ Arijit Das, Tutor, Department of Pharmacology, Diamond Harbour Medical College, West Bengal, India.

Background: Keeping in view the great variations in different dimensions of the human trachea and its remarkable clinical importance, the present work was undertaken. It included the study of dimensions of adult trachea of both sexes in West Bengal population. In addition, an effort was made to establish their relationship with selected external measurements. Methods: This was a cross-sectional, observational study on 60 cadavers. Relatively disease-free fresh adult cadavers were selected from West Bengal population. Study variables were tracheal length, internal transverse diameter and internal anteroposterior diameter. Selected external measurements were height and sternal length. Results: In males, the highest correlation was observed between tracheal length and height $(r=0.800)$, and tracheal length and sternal length $(r=0.799)$. In females, the highest correlation coefficient was found between tracheal length and height $(r=0.809)$. Conclusion: Different formulae were obtained by linear regression with all measurements being in centimeters. Therefore, it is possible to predict the tracheal dimensions from simple external measurements.

Keywords: Tracheal length, Internal transverse diameter, Internal anteroposterior diameter, Height, Sternal length

Corresponding Author

Dipankar Kundu, Associate Professor, Department of Biochemistry, Medical College, Kolkata, West Bengal, India.

Email: dr.dipankar@yahoo.co.in
How to Cite this Article

Datta D, Kundu D, Pal S, Das A. A morphometric study of adult human trachea in West Bengal population. Int J Med Res Rev. 2019;7(1):36-42. Available From

https://ijmrr.medresearch.in/index.php/ijmrr/article/ view/1033
To Browse

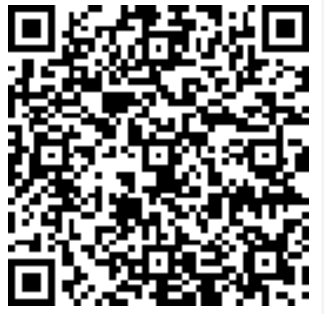
2019 by Dibyendu Datta, Dipankar Kundu, Sharmila Pal, Arijit Das and Published by Siddharth Health Research and Social
Welfare Society. This is an Open Access article licensed under a Creative Commons Attribution 4.0 International License https://creativecommons.org/licenses/by/4.0/ unported [CC BY 4.0].

\section{Manuscript Received} 2019-02-04

Conflict of Interest No

Review Round 1
2019-02-14
Funding
Nil

\section{Review Round 3}

Accepted 2019-02-22

Note 


\section{Introduction}

The trachea is an unpaired hollow tube which lies approximately in the sagittal plane. It descends as a continuation of the larynx from the level of the sixth cervical vertebra to the upper border of the fifth thoracic vertebra, where it divides into right and left principal bronchi [1]. Accurate anatomical knowledge regarding the dimensions of the trachea has immense importance in anesthesiology, reconstructive surgery and other clinical fields.

There is a wide variation in different dimensions and shapes of trachea described in different textbooks and journals.The book, "Gray's Anatomy" by Standring states that adult trachea is $10-11 \mathrm{~cm}$ long. Its external transverse diameter is typically 2 $\mathrm{cm}$ in adult males, and $1.5 \mathrm{~cm}$ in adult females. The lumen in live adults has an average transverse diameter of $12 \mathrm{~mm}$, although this increases after death because smooth muscle making up its posterior aspect relaxes. The transverse shape of the lumen is variable, especially in later decades of life, and may be round, lunate or flattened [1]. According to the book, "Principles of Surgery" by Schwartz the adult trachea has an average length of $11 \mathrm{~cm}$ (range 10 to $13 \mathrm{~cm}$ ) segmented by 18-22 semicircular cartilage rings and has elliptical internal dimension averaging $2.3 \mathrm{~cm}$ in transverse diameter and $1.8 \mathrm{~cm}$ in anteroposterior diameter [2].

Kiriluk and Merendino studied the length and diameters of the trachea and principal bronchi in 136 cadavers of both sexes. The data reported did not represent a detailed analysis of the measurements taken [3]. Griscom and Wohl measured dimensions of the growing trachea in relation to height of the individual, length, anteroposterior and transverse diameters, cross sectional area, and volume of the trachea in subjects younger than 20 years of age using computed tomography [4]. Cadaveric dissection studies on trachea were replaced by CT based studies because of easy accessibly to study subjects of different age groups. However, Randestad et al reported that the cadaveric studies should have less measurement errors [5]. Anthropometric variables are individual characteristics and their range of normality differs between races and even ethnic groups in the same race [6].

Population based study on the anthropometric variables like the dimensions of trachea and other large airways have not received adequate attention in the past decades.
There is a wide variation in different dimensions of the major components of human tracheobronchial tree in a same age group as well as in different age groups in both sexes.

Different anatomical landmarks were used in various studied for prediction of airway length with variable success. By linear regression, Cherng et al. obtained a formula to estimate the optimal endotracheal tube length in intubated patients [7].

Techanivate et al. found moderate correlation between height of a person and canine to carinal length [8]. Evron et al. used some topographic methods for detection of airway length [9].

Mukherjee et al. conducted a study for bedside prediction of airway length by measuring upper incisor-manubriosternal joint length [10].

Keeping the above factors in limelight, the present population-based study (cross-sectional, observational study) was conducted to measure the tracheal dimensions from adult cadavers.

In addition, an effort was made to establish their relationship with selected external measurements. Different formulae were obtained by linear regression to predict the airway length and diameters.

\section{Aims and Objectives}

To study the morphometric variations of adult human trachea (tracheal length, internal transverse diameter, internal anteroposterior diameter) in West Bengal population and to evaluate relationship between the tracheal measurements and selected external measurements (height and sternal length)

\section{Materials and Methods}

Study setting: The present study was conducted on 60 cadavers in Kolkata Police Morgue and Department of Anatomy, Medical College, Kolkata over a span of one year after acceptance of the research proposal by Institutional Ethics Committee.

Type of study: It was a cross-sectional, observational study.

Sampling methods: A total number of 60 cadavers (30 adult males and 30 adult females) aged between 20 and 65 years were selected by random sampling. An official document to substantiate their birth in West Bengal was sought. 
Attempts were made to collect the specimens from relatively fresh and disease free cadavers.

Inclusion criteria: (a) Both sexes with age between 20 and 65 years (b) disease free fresh cadavers

Exclusion criteria: (a) Age of cadavers less than 20 years and more than 65 years (b) cadavers passed more than 24 hours of death (c) mutilated cadavers (d) unidentified cadavers and (e) tracheal abnormalities and thoracic abnormalities including deformities of sternum.

Measurements and dissections: Data were collected on gender and age. Selected external measurements were recorded in centimeters with the help of standard measuring tape. Autopsy specimens of trachea with right and left principal bronchi, and part of the larynx were collected. Selected tracheal dimensions were measured in centimeters with the help of standard measuring scale and slide-caliper.

The cadaver was kept on the dissection table lying supine, keeping the head erect and looking straight ahead. Height was measured from the vertex to the heel. Sternal length was taken from the suprasternal notch to the lower end of xiphoid process.

Dimensions of trachea were measured after proper dissection of the autopsy specimen. Tracheal length was measured from the lower border of the cricoid cartilage to the lower border of the carina. A segment of trachea, about $1 \mathrm{~cm}$ thick, was cut at the junction between the upper third and middle third of the tracheal length.

Shape of the dissected segment was noted and internal transverse diameter (in midcoronal plane) and internal anteroposterior diameter (in midsagittal plane) were measured.

All the measurements obtained from the study were tabulated by using appropriate charts. Finally, relationship between standardized measurements of trachea and selected external measurements were statistically evaluated.

\section{Results}

A total number of sixty specimens of trachea were collected from thirty adult male and thirty adult female cadavers. Selected external dimensions like height and sternal length (SL) of each cadaver were measured.
Data on tracheal length ( $T L)$, internal transverse diameter (TD) and internal anteroposterior diameter (APD) were collected from each specimen of trachea.

Statistical analysis of the data has been performed using MINITABTM Statistical Software (version: 13.31, Minitab Inc. PA, USA). The t-test has been used to test whether correlation between an external measurement and a tracheal measurement is significant or not. Linear regression lines are drawn to indicate the linear relationship between two correlated variables. A p-value of less than 0.05 is considered to indicate statistical significance.

Tables 1 and 2 give the range, mean and standard deviation of the selected external measurements in male and female subjects, while Tables 3 and 4 give the tracheal measurements taken on the specimens of trachea.

Table-1: External measurements in males.

\begin{tabular}{|l|l|l|}
\hline \multicolumn{1}{|c|}{ Males } & \multicolumn{1}{c|}{ Range } & \multicolumn{1}{c|}{ Mean + SD } \\
\hline Height $(\mathrm{cm})$ & $145-182$ & $164.43+11.23$ \\
\hline $\mathrm{SL}(\mathrm{cm})$ & $16-22$ & $19.17+1.58$ \\
\hline
\end{tabular}

Table-2: External measurements in females.

\begin{tabular}{|l|l|l|}
\hline \multicolumn{1}{|c|}{ Females } & \multicolumn{1}{c|}{ Range } & \multicolumn{1}{c|}{ Mean + SD } \\
\hline Height $(\mathrm{cm})$ & $138-174$ & $149.73+9.02$ \\
\hline $\mathrm{SL}(\mathrm{cm})$ & $16-19$ & $17.23+1.22$ \\
\hline
\end{tabular}

Table-3: Tracheal measurements in males.

\begin{tabular}{|l|l|l|}
\hline \multicolumn{1}{|c|}{ Males } & \multicolumn{1}{c|}{ Range } & \multicolumn{1}{c|}{ Mean + SD } \\
\hline TL $(\mathrm{cm})$ & $9.7-11.2$ & $10.42+0.495$ \\
\hline TD $(\mathrm{cm})$ & $1.1-1.5$ & $1.29+0.124$ \\
\hline APD $(\mathrm{cm})$ & $1.2-1.8$ & $1.55+0.183$ \\
\hline
\end{tabular}

Table-4: Tracheal measurements in females.

\begin{tabular}{|l|l|l|}
\hline \multicolumn{1}{|c|}{ Females } & \multicolumn{1}{c|}{ Range } & \multicolumn{1}{c|}{ Mean + SD } \\
\hline TL $(\mathrm{cm})$ & $9.4-10.4$ & $9.81+0.233$ \\
\hline TD $(\mathrm{cm})$ & $1.1-1.5$ & $1.20+0.103$ \\
\hline APD $(\mathrm{cm})$ & $1.1-1.7$ & $1.37+0.132$ \\
\hline
\end{tabular}

Tables 5 to 7 present the correlation coefficients between external measurements and tracheal measurements along with the corresponding $p$ values.

Table-5: External measurements and TL.

\begin{tabular}{|l|l|l|}
\hline \multicolumn{1}{|c|}{ All subjects } & \multicolumn{1}{|c|}{ Correlation coefficients } & \multicolumn{1}{c|}{ p-values } \\
\hline Height $(\mathrm{cm})$ & 0.861 & $<0.001$ \\
\hline $\mathrm{SL}(\mathrm{cm})$ & 0.820 & $<0.001$ \\
\hline
\end{tabular}

Table-6: External measurements and TD.

\begin{tabular}{|l|l|l|}
\hline \multicolumn{1}{|c|}{ All subjects } & \multicolumn{1}{|c|}{ Correlation coefficients } & \multicolumn{1}{c|}{ p-values } \\
\hline Height $(\mathrm{cm})$ & 0.290 & 0.024 \\
\hline
\end{tabular}


$\mathrm{SL}(\mathrm{cm})$

0.299

0.020

Table-7: External measurements and APD.

\begin{tabular}{|l|l|l|}
\hline \multicolumn{1}{|c|}{ All subjects } & \multicolumn{1}{|c|}{ Correlation coefficients } & \multicolumn{1}{c|}{ p-values } \\
\hline Height $(\mathrm{cm})$ & 0.508 & $<0.001$ \\
\hline $\mathrm{SL}(\mathrm{cm})$ & 0.480 & $<0.001$ \\
\hline
\end{tabular}

In males, the highest correlation was observed between tracheal length and height $(r=0.800)$, and tracheal length and sternal length $(r=0.799)$. In females, the highest correlation coefficient was observed between tracheal length and height ( $r=$ 0.809). When all the subjects were taken together, tracheal length, internal transverse diameter and internal anteroposterior diameter showed significant correlation with height, and sternal length. Following figures show the linear regression lines of tracheal measurements on general characteristics with which there is significant correlation.

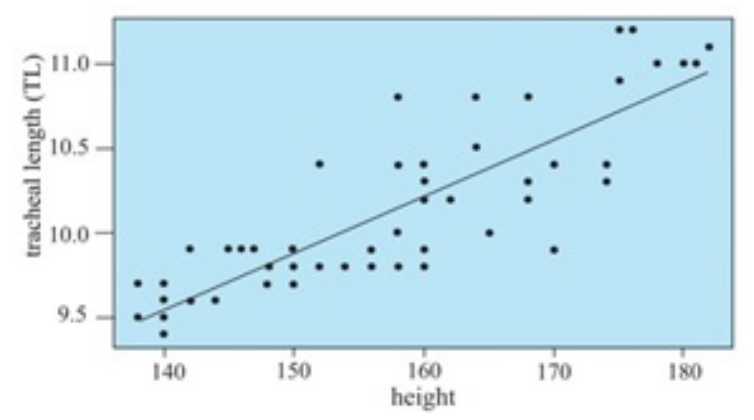

Figure-1 $\left(T L=4.822+0.034^{\prime}\right.$ Height $)$

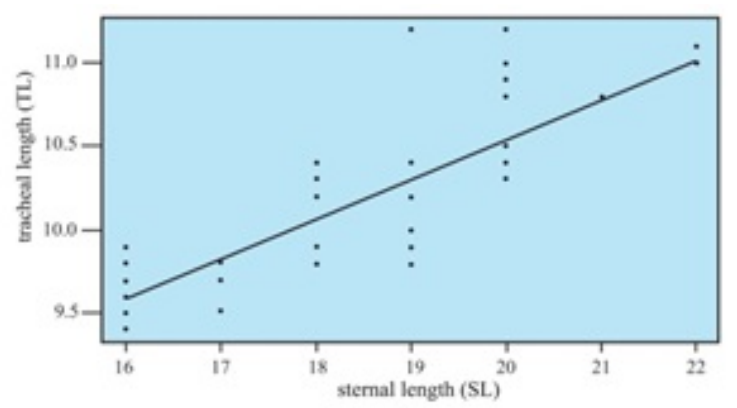

Figure-2 ( $\left.T L=5.821+0.236^{\prime} \mathrm{SL}\right)$

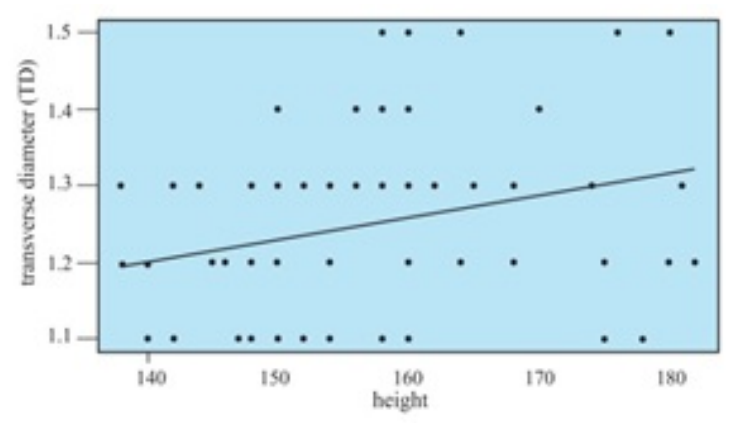

Figure-3 (TD=0.803+0.003' Height)

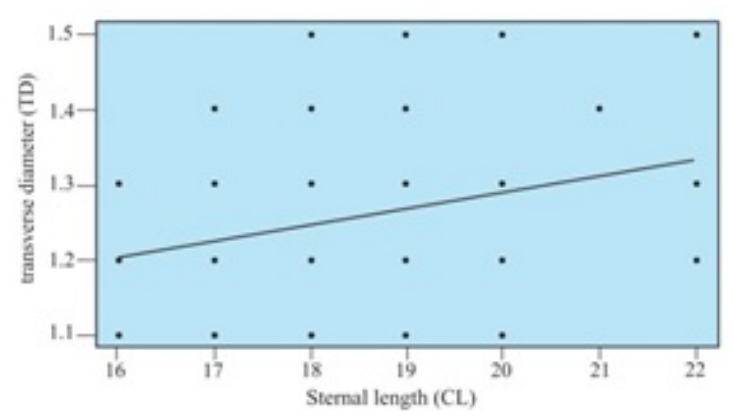

Figure-4 (TD=0.803+0.003'SL)

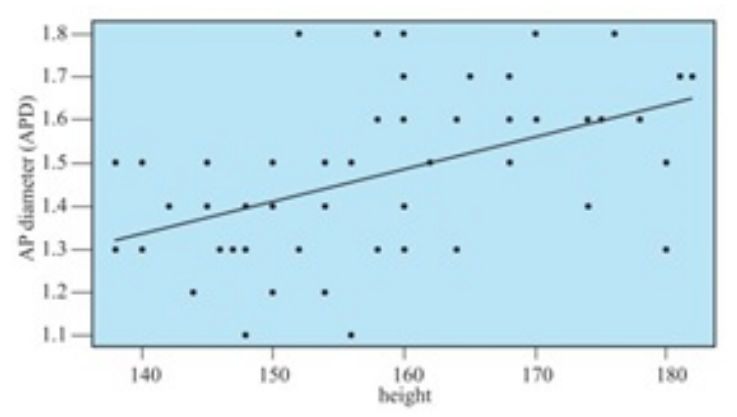

Figure-5 (APD=0.294+0.007' Height)

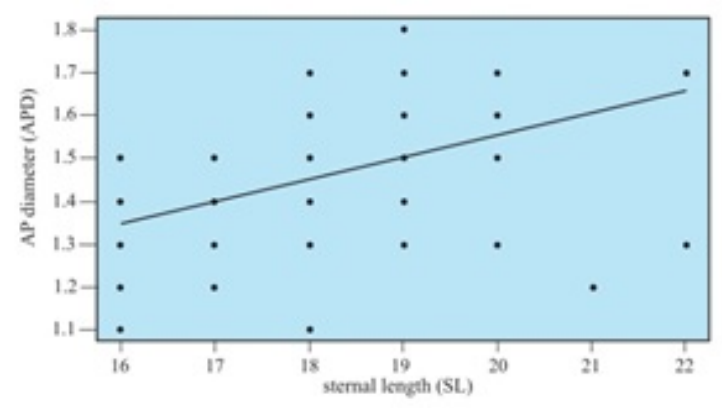

Figure-6 $\left(A P D=1.107+0.041^{\prime} S L\right)$

\section{Discussion}

In the present study, the average tracheal length was $10.42+0.495 \mathrm{~cm}$ (range: $9.7-11.2 \mathrm{~cm}$ ) in males and $9.81+0.233 \mathrm{~cm}$ (range: $9.4-10.4 \mathrm{~cm}$ ) in females. The values showed similarity with the studies conducted by Chunder et al [11] and Pak et al. [12] but the values were higher than those described by Begam et al. [13] and MunguiaCanales et al [14].

The range of variations in the internal diameters of trachea is greater than that described in different anatomy texts. The racial factors may be responsible for such variations [15]. 
Shape of the trachea and principal bronchi are not uniform in a single specimen from above downwards [16]. In the present study, the average internal transverse diameter in males was $1.29+0.124 \mathrm{~cm}$. and the range was $1.1-1.5 \mathrm{~cm}$. In females, the average internal transverse diameter was $1.20+$ $0.103 \mathrm{~cm}$. and the range was $1.1-1.5 \mathrm{~cm}$. Breatnach et al. (1984) described that the coronal diameters were $13-25 \mathrm{~mm}$ in men and $10-21 \mathrm{~mm}$ in women [17].

According to the study conducted by Chunder et al. the average internal transverse diameters of the upper trachea were $1.24 \mathrm{~cm}$ and $1.22 \mathrm{~cm}$ and that of the lower trachea were $1.2 \mathrm{~cm}$ and $1.1 \mathrm{~cm}$ in adult males and females respectively [11].

Zahedi-Nezad et al. (2011) reported that the mean coronal diameters of trachea in the upper part were $1.8+0.24 \mathrm{~cm}$ for men and $1.48+0.20 \mathrm{~cm}$ for women, and the mean coronal diameters of trachea in the lower part were $1.8+0.23 \mathrm{~cm}$ for men and $1.51+0.18 \mathrm{~cm}$ for women [18].

Prasanna Kumar and Ravikumar (2014) found that the mean coronal diameter of trachea in adult Indian male ranged from $13.18 \mathrm{~mm}$ to $17.68 \mathrm{~mm}$ and the mean coronal diameter of adult Indian female ranged from $8.7 \mathrm{~mm}$ to $15.34 \mathrm{~mm}$ [19]. According to Munguia-Canales et al. (2011) the average internal transverse tracheal diameters in the upper third of trachea were $1.9+0.2 \mathrm{~cm}$ in male and $1.7+0.3 \mathrm{~cm}$ in female [14].

In this study, the average internal anteroposterior diameter at the level of the junction between the upper third and middle third of the tracheal length in males was $1.55+0.183 \mathrm{~cm}$ and the range was $1.2-1.8 \mathrm{~cm}$. In females, the average internal anteroposterior diameter was $1.37+0.132 \mathrm{~cm}$ and the range was $1.1-1.7 \mathrm{~cm}$.

Breatnach et al. found that the sagittal diameters were $13-27 \mathrm{~mm}$ in men and $10-23 \mathrm{~mm}$ in women [17]. According to Zahedi-Nezad et al. (2011) the mean sagittal diameters of trachea in the upper part were $2.06+0.27 \mathrm{~cm}$ for men and $1.49+0.24 \mathrm{~cm}$ for women, and the mean sagittal diameters of trachea in the lower part were $1.86+0.27 \mathrm{~cm}$ for men and $1.46+0.23 \mathrm{~cm}$ for women [18]

Munguia-Canales et al. (2011) found in their study that the average internal anteroposterior tracheal diameters in the upper third of trachea were $1.8+$ $0.3 \mathrm{~cm}$ in male and $1.6+0.3 \mathrm{~cm}$ in female [14].
Different anatomical landmarks were used in various studied for prediction of airway length with variable success. Cherng et al. obtained a formula to estimate the optimal endotracheal tube length in orotracheally intubated patients: the length from 5 $\mathrm{cm}$ above carina to right mouth angle $(\mathrm{cm})=$ [body height $(\mathrm{cm}) / 5$ ] - 13. The proposed formula can provide a useful guide to estimate the optimal endotracheal tube tip position [7].

Techanivate et al. suggested formulae for determining required length of the endotracheal tube [8]. According to the formulae, length of oral endotracheal tube $(\mathrm{cm})=$ height $(\mathrm{cm}) / 10+4$ and length of nasal endotracheal tube $(\mathrm{cm})=$ height $(\mathrm{cm}) / 10+9$.

In the present study, following formulae were obtained by linear regression with all measurements being in centimeters. Tracheal length $=4.822+$ $0.034^{\prime}$ Height. Tracheal length $=5.821+0.236$ 'Sternal length. Internal transverse diameter $=0.803+0.003$ ' Height.

Internal transverse diameter $=0.803+0.003$ Sternal length. Internal anteroposterior diameter $=0.294$ $+0.007^{\prime}$ Height. Internal anteroposterior diameter= $1.107+0.041^{\prime}$ 'Sternal length. Therefore, it is possible to predict the airway length by making simple external measurements.

\section{Conclusion}

Knowledge regarding the anatomy of trachea is essential for airway management, tracheobronchial resection and reconstruction procedures and for understanding the pathophysiology of different airway disorders. There is a wide variation in different dimensions of human trachea in same age group as well as in different age groups in both sexes.

\section{What this study adds to existing knowledge}

Keeping in view the great variations in tracheal dimensions, the present work was undertaken. It included the study of different dimensions of trachea in adults of both sexes from West Bengal population. In addition, an effort was made to establish their relationship with two selected external measurements. By linear regression, different formulae were obtained to estimate the tracheal length and diameters from height and sterna length. 
This study was conducted after receiving approval from the institutional ethical committee of Medical College, Kolkata. All the authors were involved in collection of data, statistical analysis and manuscript preparation. The authors declare no conflicts of interest. The study was not supported by any grants or funding agencies. We would like to thank the management of Medical College, Kolkata.

\section{Reference}

01. Standring S, Gatzoulis MA, Collins P, Healy JC, Wigley C. Thorax Gray's Anatomy, 40th edition. Edin Churchill Livingstone. 2008;1000-06. [Crossref]

02. Schwartz SI, Rusch VW, Ginsberg RJ. Chest wall, pleura, lung and mediastinum. Principles of Surgery, 7th edition, McGraw-Hill. 1999;764. [Crossref]

03. Kiriluk LB, Merendino KA. An experimental evalu ation of bronchial anastomosis and healing with special consideration of plane of transaction. Surg Gynecol Obstet. 1953 Feb;96(2)175-182. [Crossref]

04. Griscom NT, Wohl ME. Dimensions of the growing trachea related to body height, Length, anteroposterior and transverse diameters, cross-sectional area, and volume in subjects younger than 20 years of age. Am Rev Respir Dis. 1985 Jun;131(6)840-4.

DOI: 10.1164 /arrd.1985.131.6.840

[Crossref]

05. Randestad A, Lindholm CE, Fabian P. Dimensions of the cricoid cartilage and the trachea. Laryngoscope. 2000 Nov;110(11)1957-61.

DOI: $\quad 10.1097 / 00005537-200011000-00036$ [Crossref]

06. Giles E, Klepinger LL. Confidence intervals for estimates based on linear regression in forensic anthropology. J Forensic Sci. 1988 Sep;33(5)1218-22.

[Crossref]

07. Cherng $\mathrm{CH}$, Wong $\mathrm{CS}$, $\mathrm{Hsu} \mathrm{CH}$, et al. Airway length in adults- estimation of the optimal endotracheal tube length for orotracheal intubation. J Clin Anesth. 2002 Jun;14(4)271-4. [Crossref]

08. Techanivate A, Rodanant O, Charoenraj P, et al. Depth of endotracheal tubes in Thai adult pat ients. J Med Assoc Thai. 2005 Jun;88(6)775-81. [Crossref]
09. Evron S, Weisenberg M, Harow E, et al. Proper insertion depth of endotracheal tubes in adults by topographic landmarks measurements. J Clin Anesth. 2007 Feb;19(1)15-9.

DOI: $10.1016 /$ j.jclinane.2006.06.005

[Crossref]

10. Mukherjee S, Ray M, Pal R. Bedside prediction of airway length by measuring upper incisormanubriosternal joint length. J Anaesthesiol Clin Pharmacol. 2014;30(2)188-94. doi: $10.4103 / 0970-9185.130011$ [Crossref]

11. Chunder $R$, Nandi $S$, Guha $R$, et al. $A$ morphometric study of human trachea and principal bronchi in different age groups in both sexes and its clinical implications. Nepal Med Coll J. 2010 Dec;12(4)207-14.

[Crossref]

12. Pak $\mathrm{HJ}$, Hong $\mathrm{BH}$, Lee WH. Assessment of airway length of Korean adults and children for otolaryngology and ophthalmic surgery using a fiberoptic bronchos-cope. Korean J Anesthesiol. 2010 Oct;59(4)249-55.

doi: $\quad 10.4097 / \mathrm{kjae} .2010 .59 .4 .249 \quad$ [Crossref]

13. Begum T, Naushaba H, Alam J, Paul UK, Alim AJ, Akter J, Ahmed R. Cadaveric length of trachea in Bangladeshi adult male. Bangladesh J Anat. 2009;7;1(1)42-44.

[Crossref]

14. Munguía-Canales DA, Ruiz-Flores J, VargasMendoza GK, et al. Tracheal dimensions in the Mexican population. Cir Cir. 2011NovDec;79(6)505-10.

[Crossref]

15. Kamel KS, Lau G, Stringer MD. In vivo and in vitro morphometry of the human trachea. Clin Anat. 2009 Jul;22(5)571-9. doi: $10.1002 /$ ca.20815 [Crossref]

16. Jesseph JE, Merendino KA. The dimensional interrelationships of the major components of the human tracheobronchial tree. Surg Gynecol Obstet. 1957 Aug;105(2)210-4.

[Crossref]

17. Breatnach E, Abbott GC, Fraser RG. Dimensions of the normal human trachea. AJR Am J Roentgenol. 1984 May;142(5):903-6.

DOI: $10.2214 /$ ajr.142.5.903 [Crossref] 
18. Zahedi-Nejad N, Bakhshayesh-Karam M, Kahkoei $S$, et al. Normal dimensions of trachea and two main bronchi in the Iranian population. Pol J Radiol. 2011 Oct; 76(4)28-31.

[Crossref]
19. Prasanna Kumar S, Ravikumar A. Biometric study of the internal dimensions of subglottis and upper trachea in adult Indian population. Indian J Otolaryngol Head Neck Surg. 2014 Jan; 66(Suppl 1)261-6.

doi: $10.1007 / \mathrm{s} 12070-012-0477-x \quad$ [Crossref] 